\title{
Aerococcus urinae Isolated from Women with Lower Urinary Tract Symptoms: In Vitro Aggregation and Genome Analysis
}

\author{
Evann E. Hilt \\ Loyola University Chicago \\ Catherine Putonti \\ Loyola University Chicago, cputonti@luc.edu \\ Krystal Thomas-White \\ Loyola University Chicago \\ Amanda L. Lewis \\ Washington University School of Medicine \\ Karen L. Visick \\ Loyola University Chicago
}

See next page for additional authors

Follow this and additional works at: https://ecommons.luc.edu/bioinformatics_facpub

Part of the Bioinformatics Commons

\section{Recommended Citation}

Hilt EE, Putonti C, Thomas-White K, Lewis AL, Visick KL, Gilbert NM, Wolfe AJ. 2020. Aerococcus urinae isolated from women with lower urinary tract symptoms: in vitro aggregation and genome analysis. $J$ Bacteriol 202:e00170-20. https://doi.org/10.1128/JB.00170-20.

This Article is brought to you for free and open access by the Faculty Publications and Other Works by Department at Loyola eCommons. It has been accepted for inclusion in Bioinformatics Faculty Publications by an authorized administrator of Loyola eCommons. For more information, please contact ecommons@luc.edu. cc) (i) $\odot$

This work is licensed under a Creative Commons Attribution-Noncommercial-No Derivative Works 3.0 License. (c) American Society for Microbiology, 2020. J Bacteriol 202:e00170-20. https://doi.org/10.1128/JB.00170-20. 


\section{Authors}

Evann E. Hilt, Catherine Putonti, Krystal Thomas-White, Amanda L. Lewis, Karen L. Visick, Nicole M. Gilbert, and Alan J. Wolfe 


\title{
Aerococcus urinae Isolated from Women with Lower Urinary Tract Symptoms: In Vitro Aggregation and Genome Analysis
}

\author{
Evann E. Hilt, ${ }^{a *}$ (D) Catherine Putonti, ${ }^{a, b, c, d}$ Krystal Thomas-White, ${ }^{a *}$ Amanda L. Lewis, ${ }^{\text {e }}$ (D) Karen L. Visick, ${ }^{a}$ \\ (i) Nicole M. Gilbert, ${ }^{e, f}$ Alan J. Wolfe ${ }^{a}$ \\ aDepartment of Microbiology and Immunology, Stritch School of Medicine, Loyola University Chicago, Maywood, Illinois, USA \\ bDepartment of Biology, Loyola University Chicago, Chicago, Illinois, USA \\ 'Department of Computer Science, Loyola University Chicago, Chicago, Illinois, USA \\ dBioinformatics Program, Loyola University Chicago, Chicago, Illinois, USA \\ eCenter for Women's Infectious Disease Research, Department of Molecular Microbiology, Washington University School of Medicine, St. Louis, Missouri, USA \\ ${ }^{\mathrm{f} C e n t e r}$ for Reproductive Health Sciences, Department of Obstetrics and Gynecology, Washington University School of Medicine, St. Louis, Missouri, USA
}

ABSTRACT Aerococcus urinae is increasingly recognized as a potentially significant urinary tract bacterium. A. urinae has been isolated from urine collected from both males and females with a wide range of clinical conditions, including urinary tract infection (UTI), urgency urinary incontinence (UUI), and overactive bladder (OAB). A. urinae is of particular clinical concern because it is highly resistant to many antibiotics and, when undiagnosed, can cause invasive and life-threatening bacteremia, sepsis, or soft tissue infections. Previous genomic characterization studies have examined $A$. urinae strains isolated from patients experiencing UTI episodes. Here, we analyzed the genomes of $A$. urinae strains isolated as part of the urinary microbiome from patients with UUI or OAB. Furthermore, we report that certain $A$. urinae strains exhibit aggregative in vitro phenotypes, including flocking, which can be modified by various growth medium conditions. Finally, we performed in-depth genomic comparisons to identify pathways that distinguish flocking and nonflocking strains.

IMPORTANCE Aerococcus urinae is a urinary bacterium of emerging clinical interest. Here, we explored the ability of 24 strains of $A$. urinae isolated from women with lower urinary tract symptoms to display aggregation phenotypes in vitro. We sequenced and analyzed the genomes of these $A$. urinae strains. We performed functional genomic analyses to determine whether the in vitro hyperflocking aggregation phenotype displayed by certain $A$. urinae strains was related to the presence or absence of certain pathways. Our findings demonstrate that $A$. urinae strains have different propensities to display aggregative properties in vitro and suggest a potential association between phylogeny and flocking.

KEYWORDS Gram positive, aggregation, bladder, lower urinary tract symptoms, urinary microbiome

\footnotetext{
- he urinary tract is one of the most common sites of bacterial infection. In addition to detecting recognized uropathogens such as Escherichia coli, hospital microbiology labs routinely find "clinically insignificant" numbers of bacteria in urine. Recent studies have revealed evidence of diverse microbes (the microbiota) in the urinary bladders of many adults (1-4). Furthermore, these studies have found that the microbiota of adult female bladders differ between women with and without lower urinary tract symptoms, including those of urgency urinary incontinence (UUI) and urinary tract infection (UTI) $(5,6)$. Several bacterial genera, often the Gram-positive Actinotignum (formerly Actinobaculum), Streptococcus, and Aerococcus, are being referred to as "emerging uropathogens," since they have been isolated in large numbers in urine
}

Citation Hilt EE, Putonti C, Thomas-White K Lewis AL, Visick KL, Gilbert NM, Wolfe AJ. 2020. Aerococcus urinae isolated from women with lower urinary tract symptoms: in vitro aggregation and genome analysis. J Bacteriol 202:e00170-20. https://doi.org/10.1128/JB $.00170-20$.

Editor Michael J. Federle, University of Illinois at Chicago

Copyright $\odot 2020$ American Society for Microbiology. All Rights Reserved.

Address correspondence to Nicole M. Gilbert, gilbert@wustl.edu, or Alan J.Wolfe, awolfe@luc.edu.

* Present address: Evann E. Hilt, Department of Pathology and Laboratory Medicine, University of California Los Angeles, Los Angeles,

California, USA; Krystal Thomas-White Department of Microbiology \& Immunology, Stanford University School of Medicine, Stanford, California, USA

Received 30 March 2020

Accepted 3 April 2020

Accepted manuscript posted online 13 April 2020

Published 9 June 2020 
samples from patients exhibiting lower urinary tract symptoms and have been increasingly implicated as causes of UTI (7). However, relatively little is known about the molecular features that enable these species to cause bacteriuria, especially in comparison to our understanding of E. coli UTI.

Aerococcus urinae is a Gram-positive alpha-hemolytic bacterium first isolated and identified from urine from patients with UTI (8). Since its discovery, A. urinae has been isolated from a wide variety of patients, both male and female, ranging from children to the elderly (9). In addition to being a suspected cause of UTI, A. urinae has been implicated in cases of bacteremia, musculoskeletal infections, infective endocarditis, and necrotizing soft tissue infection (10-13). Even though A. urinae is increasingly recognized and identified by clinical microbiology laboratories, it can still be mischaracterized as either streptococci or staphylococci, due to similarities in morphology and Gram stain results (14). Misidentification is a significant clinical concern, because $A$. urinae is highly resistant to many sulfonamides and other antibiotics used to treat UTIs. When undiagnosed or misdiagnosed, $A$. urinae can cause invasive and life-threatening sepsis $(9,15,16)$.

Previous studies have focused on A. urinae isolated from cases of UTI. In our previous studies, $A$. urinae was frequently detected in women with conditions associated with lower urinary tract symptoms, including urgency urinary incontinence (UUI) and overactive bladder $(\mathrm{OAB})(5,6,17)$. Here, we characterized $24 \mathrm{~A}$. urinae strains, isolated primarily from women experiencing lower urinary tract symptoms but not experiencing a UTI (as classically defined), for two aggregation in vitro phenotypes. We performed a comprehensive bioinformatic analysis on the whole genomes of these strains and examined the relationship between the genotypes and in vitro aggregation phenotypes.

\section{RESULTS}

Aerococcus urinae displays in vitro aggregation phenotypes. Aggregation and biofilm formation are key features for many pathogenic bacteria, including those of the urinary tract, because they aid in protection from the immune response and antimicrobial agents and thus allow for persistence (18). A previous study found that $A$. urinae induces platelet aggregation and forms biofilms on plastic in standing culture, demonstrating the aggregative capacity of this bacterium (19). We found that $A$. urinae exhibits two additional in vitro aggregation phenotypes (Fig. 1 and Table 1). The first is a "flocking" phenotype, whereby the bacteria stick to each other and aggregate during static growth in liquid culture. Of the $24 \mathrm{~A}$. urinae strains we tested, $21 \%(5 / 24)$ flocked in the two different media tested, brain heart infusion broth (BHIB) and tryptic soy broth (TSB) (Fig. 1A, middle), 25\% (6/24) flocked in one of the media, while 54\% (13/24) did not flock regardless of the medium composition we tested (Table 1; Fig. 1A, left). Three strains exhibited a "hyperflocking" phenotype in both the TSB and BHI liquid media (Fig. 1A, right); we define hyperflocking as larger aggregates that remain intact after vortexing for up to $1 \mathrm{~min}$ and when cells are washed in sterile phosphate-buffered saline (PBS) (see Fig. S1 in the supplemental material).

A second aggregation characteristic of $A$. urinae was revealed when we performed the so-called "hockey puck test," in which a bacterial colony is pushed across the surface of an agar plate supplemented with glucose. This test is used as a diagnostic tool for the respiratory pathogen Moraxella catarrhalis (20). In this test, some A. urinae colonies maintained their shape when pushed across the surface of an agar plate (Fig. $1 \mathrm{~B}$, top), while $A$. urinae colonies negative for the phenotype were unable to maintain shape (Fig. 1B, bottom). The majority of the 24 tested $A$. urinae strains (54\% [13/24]) formed the "hockey puck" phenotype regardless of the medium composition (Table 1), $29 \%(7 / 24)$ formed hockey pucks on one medium, and only $17 \%(4 / 24)$ did not form a hockey puck on either medium. When comparing the two in vitro phenotypes, some strains (5/24) were positive for both phenotypes regardless of medium composition, including the 3 hyperflocking strains; in contrast, a few strains (3/24) were negative for both phenotypes regardless of medium composition. Together, these data demon- 

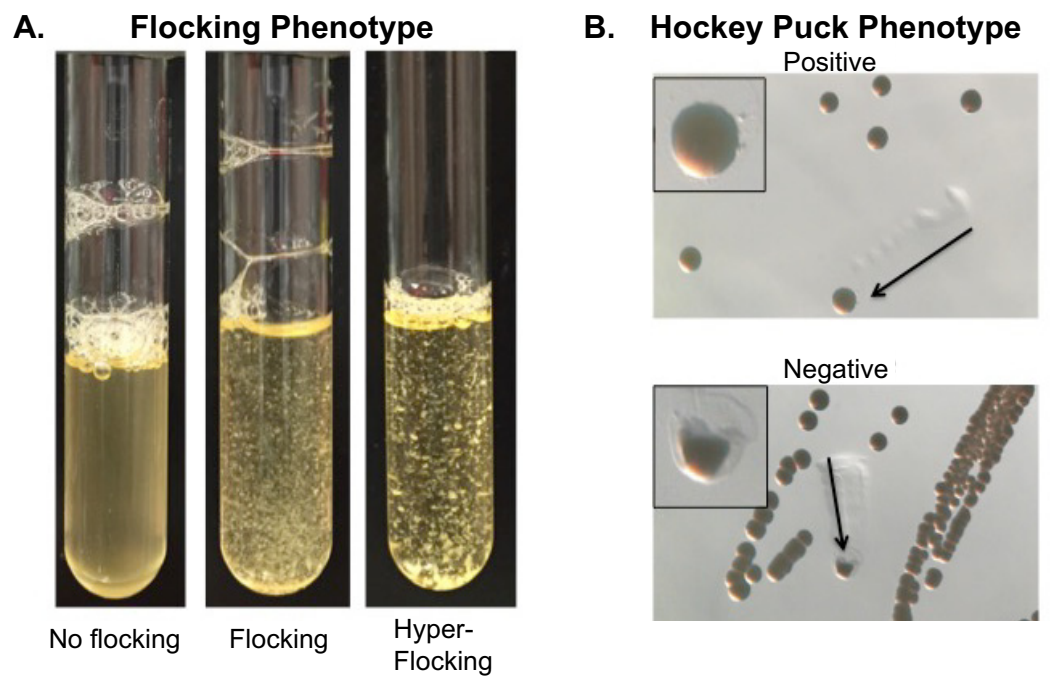

FIG 1 A. urinae urinary strains display in vitro aggregation phenotypes. (A) The flocking phenotype. $A$. urinae forms aggregates in a liquid culture when grown statically in TSB or BHI for $48 \mathrm{~h}$ under $5 \% \mathrm{CO}_{2}$ atmospheric conditions. A. urinae cells gather at the bottom of the tube, but once the tube is disturbed by flicking, the ability of $A$. urinae cells to form aggregates becomes apparent. (B) Hockey puck phenotype. When $A$. urinae is grown on $\mathrm{BHI}+\mathrm{Glu}$ (or TSA+Glu [not shown]) agar plates for $48 \mathrm{~h}$ under $5 \% \mathrm{CO}_{2}$ atmospheric conditions (strain UMB0080), the resultant colonies maintain their shape when pushed across the agar surface (indicated by the arrow and inset of top image). When $A$. urinae does not have the hockey puck phenotype (UMB0722), the colonies are unable to maintain their shape (indicated by the arrow and inset of bottom image). Experiments to observe the in vitro phenotypes were performed in triplicates more than 20 times.

strate that $A$. urinae exhibits self-adhesive properties and that phenotypic differences in these properties vary between individual strains.

Genomic diversity among $\boldsymbol{A}$. urinae strains. To gain further insight into the potential genomic basis for the phenotypic differences we observed in aggregative

TABLE 1 List of Aerococcus strains and phenotype information

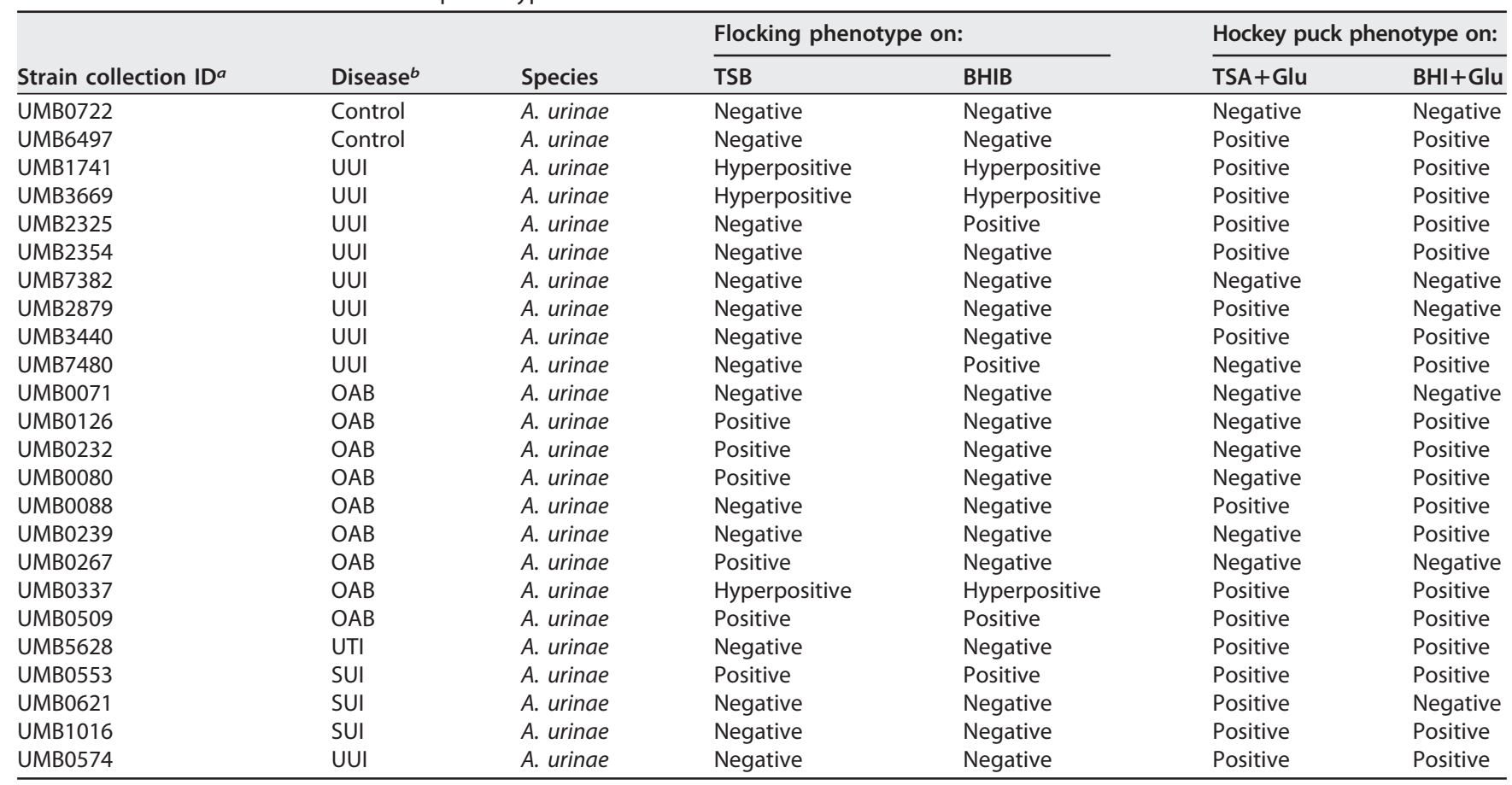

alD, identifier.

bUUI, urgency urinary incontinence; $\mathrm{OAB}$, overactive bladder; UTI, urinary tract infection; SUI, stress urinary incontinence. 


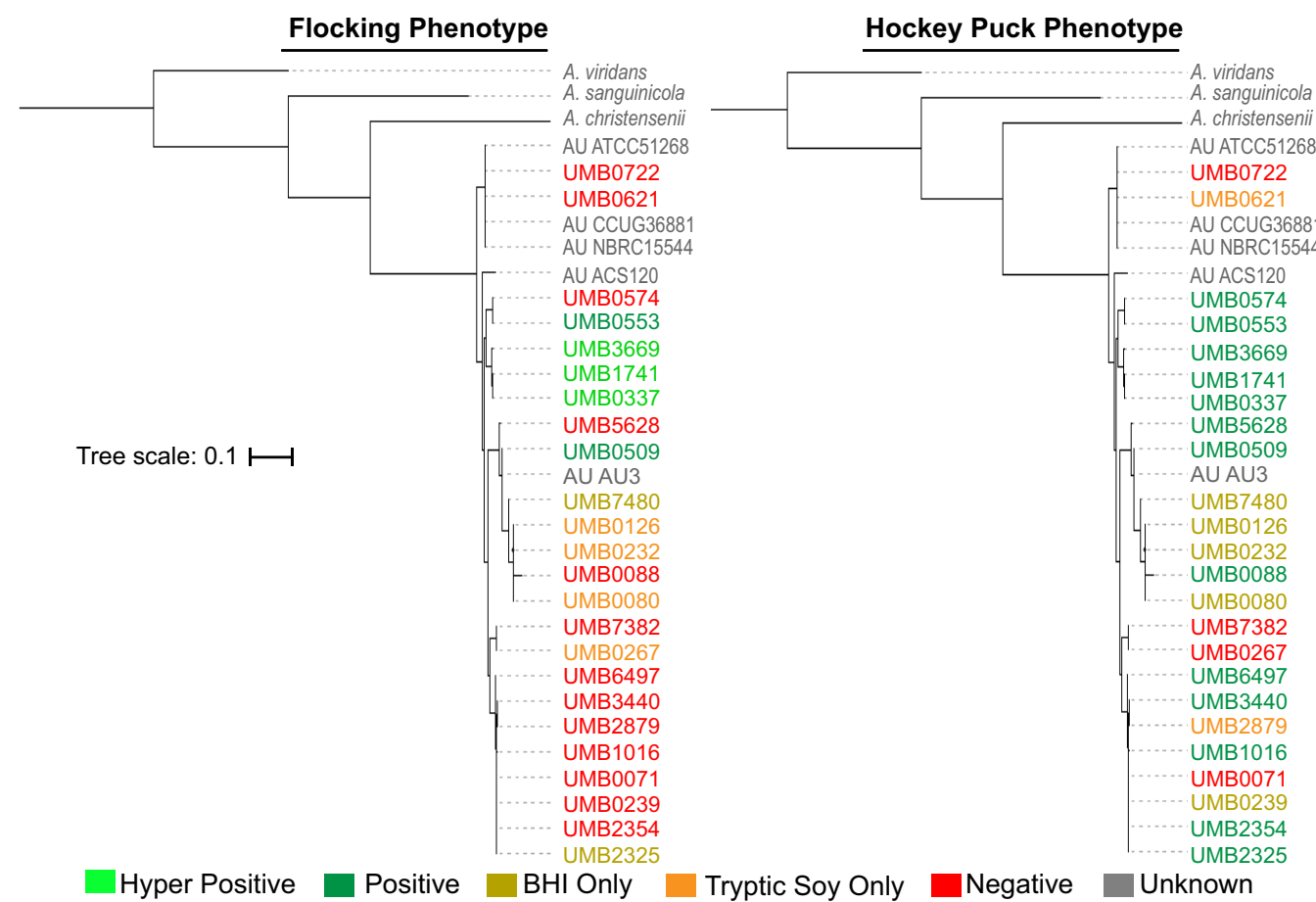

FIG 2 Core genome phylogenetic comparison of $A$. urinae urinary strains. A total of 29 A. urinae genomes were compared using 40 universal single-copy marker genes. Three other species of Aerococcus were used to root the tree. Each $A$. urinae strain from our collection was color coded based on its ability to form either the flocking or hockey puck phenotype. The tree on the left is color coded based on the flocking phenotype and the tree on the right is color coded for the hockey puck phenotype.

properties between $A$. urinae strains, we performed whole-genome sequencing. We sequenced the genomes of the $24 \mathrm{~A}$. urinae strains and those of 3 other Aerococcus species. For the $24 \mathrm{~A}$. urinae strains, the number of de novo assembled scaffolds ranged from 16 to 661 ; the genome sizes averaged $2.16 \pm 0.26 \mathrm{Mb}$, with on average 1,927 \pm 272 protein-coding regions (see Table S1). At the time we completed this study, only five $A$. urinae genomes were publicly available through GenBank. These five publicly available $A$. urinae strains were isolated from a variety of sources from human patients with diverse diagnoses (see Table S2). Genome annotation of the five previously sequenced genomes and our 24 newly sequenced genomes revealed a core $A$. urinae genome composed of 1,355 genes (see Table S3). The vast majority of the functionality encoded in the core genome remains unknown, as only $34 \%(456 / 1355)$ of these genes have a predicted function. Nevertheless, among the proteins with annotated functions include several putative virulence factors, including a member of the hemolysin II family, and homologs of fibronectin-binding protein A, conserved virulence factor B, and choline-binding protein.

To compare the genomes of the $24 \mathrm{~A}$. urinae strains isolated from the female urinary bladder to those of the five publicly available strains, we performed a phylogenetic analysis as described in Materials and Methods. All 29 A. urinae strains were highly related (Fig. 2; see also Fig. S2). Strains within the phylogenetic trees were overlaid with color coding based on the flocking and hockey puck in vitro phenotypes. Associations were not immediately apparent with the hockey puck phenotype, as the negative strains were distributed across the tree (Fig. 2, right). In contrast, the strains positive for flocking clustered together, with the hyperflocking strains being most closely related. This suggests a potential association between phylogeny and the flocking phenotype (Fig. 2, left).

A. urinae is cytotoxic to human urothelial cells. In an effort to understand the consequence of $A$. urinae interaction with the bladder urothelium, we asked if $A$. urinae 


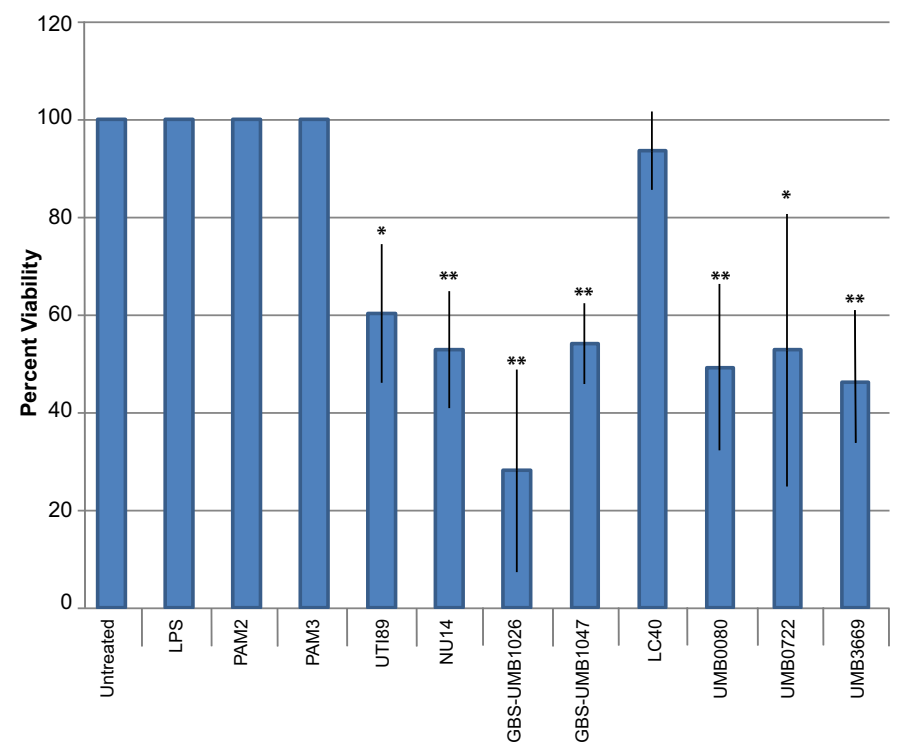

FIG 3 Percent viability of urothelial cells with various treatments at $3 \mathrm{~h}$. Three different strains of $A$. urinae were chosen for testing based on their ability to flock in two independent experiments with three intra-assay replicates in each experiment: UMB0080 is a +/- strain, UMB0722 is a -/- strain, and UMB3669 is a $+/+$ strain. For positive controls, HUCS were treated with two different strains of UPEC (NU14 and UTI89) and two strains of GBS from our UMB strain collection (UMB1026 and UMB1047). For negative controls, the HUCs were treated with various TLR agonists (LPS, Pam2, and Pam3) as well as Lactobacillus crispatus (LC40). ${ }^{*}, P<0.05,{ }^{* *}, P<0.001$. Statistics are a comparison to untreated control.

was cytotoxic to human urothelial cells (HUCs). To test the cytotoxicity effects of $A$. urinae to HUCs, we infected monolayers of HUCs with $A$. urinae strains UMB0080, UMB0722, and UMB3669 at a multiplicity of infection (MOI) of 300 (10 cells). We compared $A$. urinae cytotoxicity to that of uropathogenic $E$. coli (UPEC), group $B$ Streptococcus (GBS), and Lactobacillus crispatus (LC40) at the same MOI. At $3 \mathrm{~h}$ postinoculation (hpi), HUCs were stained with trypan blue solution to determine the percentage of cells that remained viable (Fig. 3). These results demonstrate that all three $A$. urinae strains, regardless of their ability to flock, caused a statistically significant decrease in HUC viability compared to that of untreated HUCs, with viability ranging between $45 \%$ and $60 \%$. The level of HUC cytotoxic caused by $A$. urinae was similar to those of UPEC strains UTI89 and NU14 and GBS strains UMB1026 and UMB1047 (Fig. 3). In contrast, L. crispatus (LC40) was not cytotoxic to HUCs (Fig. 3). This finding is consistent with a previous study that detected L. crispatus almost exclusively in asymptomatic women, supporting the hypothesis that L. crispatus is a commensal bacterium in the bladder (5). The observation that $A$. urinae is cytotoxic aligns with the observed presence of putative hemolysin genes and their known alpha-hemolytic behavior on blood agar and further suggests that the putative hemolysin may also be cytotoxic to the bladder epithelium

Functional annotation comparison of hyperflocking strains versus nonflocking strains. Since the three hyperflocking strains clustered together in our phylogenetic analysis (Fig. 2), we performed a more in-depth genomic analysis to determine whether these strains harbored a certain gene(s) or pathways that were absent from nonflocking strains. We assessed the gene annotations for each genome at each of the following functional classification levels: category, subcategory, subsystem, and role. Compared to the 13 nonflocking strains, the 3 hyperflocking strains were significantly enriched for coding DNA sequences (CDS) predicted to encode proteins involved in $\beta$-glucoside metabolism and L-ascorbate utilization (Fig. 4). Specifically, with respect to $\beta$-glucoside metabolism, there are 11 genes present in the hyperflocking strains that encode proteins in the pathway, and all 11 genes are absent in the nonflocking strains (see Table S4). The majority of the 11 encoded proteins are members of two phosphotrans- 
A.

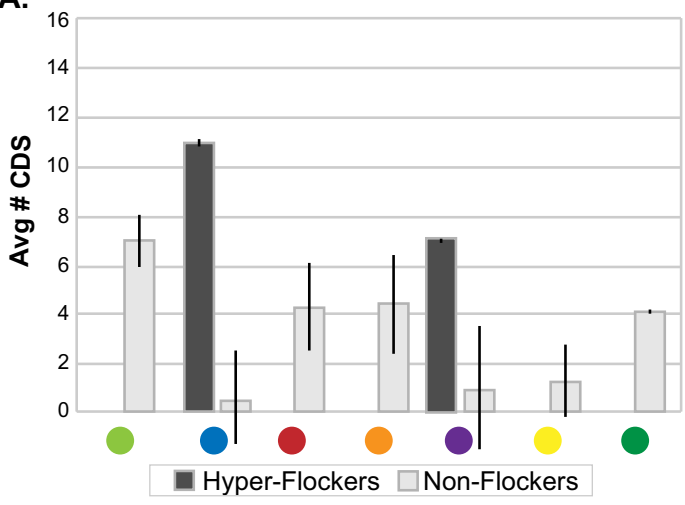

B.

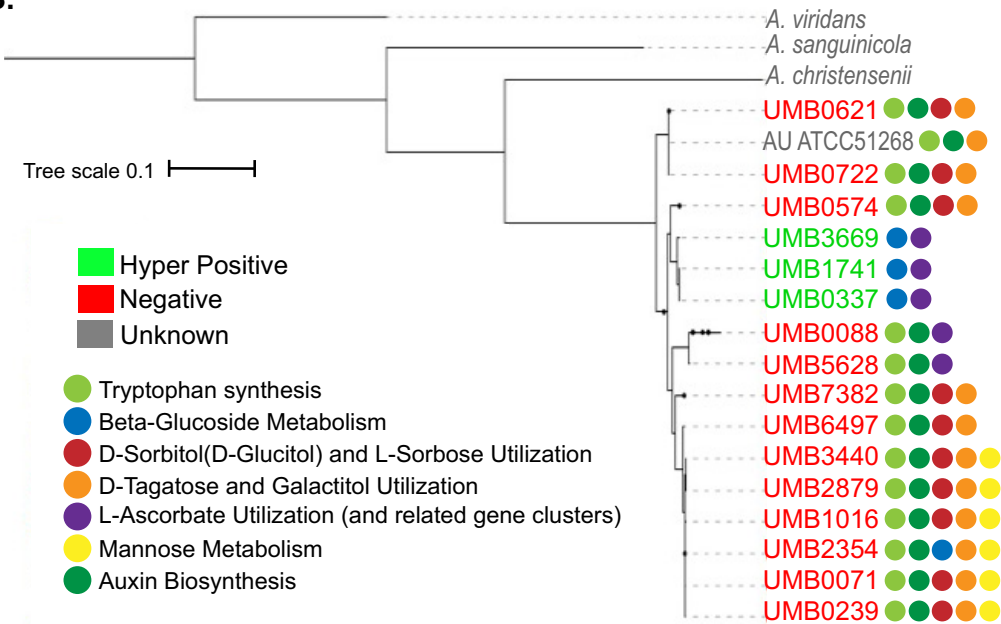

FIG 4 Functional annotation comparison of hyperflocking strains versus nonflocking strains. (A) Coding sequence difference. Average coding sequence difference between the hyperflocking and nonflocking strains. The graph is pared down to the seven specific subsystems that depict either CDS being higher in the hyperflocking strains than in nonflocking strains or completely absent from the hyperflocking strains. The colored dot under each pair of bars corresponds to the name of the subsystem in panel B. (B) Phylogenetic tree with specific subsystem comparison. This phylogenetic tree is a modified version of the trees shown in Fig. 2. This tree focuses on only the hyperflocking and nonflocking strains. Next to each strain is an array of colored dots that correspond to the specific subsystems that are present in the genome of that strain.

ferase systems (PTSs) used for importing and metabolizing $\beta$-glucoside sugars. Conversely, the hyperflocking strains were depleted for CDS involved in tryptophan synthesis, auxin biosynthesis, D-sorbitol (D-glucitol) and L-sorbose utilization, D-tagatose and galactitol utilization, and mannose metabolism (Fig. 4). In conclusion, genome comparisons revealed significant differences between hyperflocking and nonflocking strains and highlighted multiple pathways that could potentially contribute to in vitro aggregation phenotypes which can serve as a basis for future mechanistic investigations.

\section{DISCUSSION}

The recent implementation of mass spectrometry-based identification of bacteria in the clinical microbiology lab has highlighted novel agents of disease known as emerging uropathogens (7). These are primarily Gram-positive bacteria that have been repeatedly isolated in high numbers from urine samples of patients reporting lower urinary tract symptoms. One emerging uropathogen of particular interest is $A$. urinae. In the present study, we explored the in vitro ability of 24 clinical strains to display in vitro aggregative phenotypes, sequenced and analyzed their genomes, and determined whether the in vitro phenotypes correlated with their cytotoxicity, phylogeny, or genomic functional pathways.

By analyzing 24 clinical strains from cases of UUI or $O A B$, we observed two in vitro biofilm-associated phenotypes that support and extend a previous report that $A$. urinae can form biofilms (19). Depending on the growth conditions, the strains exhibited an array of phenotypic profiles. The flocking phenotype was observed in liquid media without the addition of any sugars. In contrast, the hockey puck phenotype was observed only when agar plates were supplemented with glucose. These results suggest the existence of a signal associated with sugar metabolism that induces the hockey puck phenotype. Future studies to explore the nature of those signals are needed.

The first complete genome sequence of $A$. urinae was made available in 2016 for an A. urinae strain (CCUG $36881^{\mathrm{T}}$ ) isolated from an individual experiencing a UTI episode. An additional study reported whole-genome sequences and phylogenetic characterization of $A$. urinae strains isolated from individuals experiencing episodes of UTI and bacteremia and included more male than female patients $(21,22)$. To our knowledge, 
the present study is the first comprehensive bioinformatic analysis of $A$. urinae strains isolated from the urine of women with other conditions associated with lower urinary tract symptoms (UUI and OAB). Furthermore, much of the existing literature reports $A$. urinae in males, especially in cases where it has been known to cause more invasive disease (9). This apparent male dominance likely results from a paucity of studies, as our team and others have repeatedly detected $A$. urinae in perimenopausal women with lower urinary tract symptoms $(5,6,23)$. In all of our studies combined (844 women), we have cultured $A$. urinae from a nonsymptomatic woman only twice. The vast majority have been cultured from women experiencing lower urinary tract symptoms, most often those associated with UUI and OAB. At present, it is unclear whether A. urinae is a cause of or contributor to these symptoms. While the present study focused on $A$. urinae strains isolated from patients with $\mathrm{UUI}$ or $\mathrm{OAB}$, future studies are warranted to compare these to $A$. urinae strains isolated from patients with UTI and bacteremia, both at the genomic level and with respect to in vitro aggregation phenotypes.

Although the 24 sequenced $A$. urinae strains were all highly related (Fig. 2), we identified some potentially important differences between strains based on their in vitro aggregative characteristics. Because the 3 hyperflocking strains clustered phylogenetically, we compared their genomes to those of the 13 strains that did not flock and found significant differences in their predicted metabolic capacities. The first of these differences was the complete absence from the nonflocking strains of an operon that is predicted to encode two systems for the import and initial metabolism of $\beta$-glucosides. The epithelial lining of the bladder, known as the urothelium, is lined with a polysaccharide glycosaminoglycan (GAG) layer. This GAG layer is known to contain $\beta$-linked disaccharide repeating units (24). It is possible that the ability of hyperflocking strains to metabolize these $\beta$-disaccharide units could enhance their survival in vivo. Another difference is that nonflocking strains have a complete tryptophan and auxin biosynthesis pathway, while the hyperflocking strains lack the tryptophan synthase $\alpha$ chain. The tryptophan synthase $\alpha$ chain catalyzes the last step in de novo biosynthesis of tryptophan and is thought to contribute to auxin biosynthesis (25); the absence of this gene in the hyperflocking strains suggests that they cannot synthesize tryptophan or auxin. Auxin, also known as indole-3-acetic-acid (IAA), is a phytohormone important for plant cell growth and development and is produced by both symbiotic and pathogenic plant bacteria (26). Indole has been shown to be an intercellular signaling molecule between bacteria in the gut microbiome (27), and it is possible that similar signaling events occur between $A$. urinae and the bladder microbiota. Additional studies are needed to determine the role of $\beta$-glucoside metabolism and auxin in $A$. urinae uropathogenesis.

Many well-characterized uropathogens have aggregative properties that contribute to virulence (7). Future studies using in vivo small animal models, such as mice, should examine whether the aggregative behaviors displayed by $A$. urinae in vitro are related to the ability to infect the urinary tract. It is possible that aggregative $A$. urinae strains could be better able to attach to the urothelium or avoid phagocytosis by neutrophils. It is also possible that growth under flocking-inducing conditions differentially regulates certain metabolic pathways that render A. urinae more capable of colonizing and surviving in the urinary tract. With the information gained from genomic sequencing and pathway analysis, future studies can also examine whether differing metabolic capabilities between $A$. urinae strains may also contribute to their ability to acquire nutrients and persist in the bladder. All together, these studies highlight the potential importance of $A$. urinae aggregative properties and provide important tools to further study this important urinary bacterium.

\section{MATERIALS AND METHODS}

Aerococcus urinae strain isolation, identification, and characterization. Twenty-four clinical isolates of Aerococcus urinae were collected from transurethral catheter urine samples of 21 female patients between 2013 and 2016. Following Loyola University Medical Center (LUMC) Institutional Review Board approval, patients gave verbal and written consent for chart abstraction and urine collection with analysis for research purposes. Patients were recruited as part of separate studies $(5,23,28,29)$. 
Matrix-assisted laser desorption ionization-time of flight mass spectrophotometry (MALDI-TOF MS) with the MALDI Biotyper 3.0 software program (Bruker Daltonics, Billerica, MA) was used to identify the bacterial strains, as described elsewhere (2).

The 24 clinical $A$. urinae strains were isolated from women with and without lower urinary tract symptoms (Table 1). Nine strains were collected from seven patients diagnosed with overactive bladder $(\mathrm{OAB})$, nine strains were from eight patients diagnosed with UUI, and three strains were from three patients diagnosed with stress urinary incontinence (SUI). One $A$. urinae strain was cultured from a case of UTI, as defined by patient symptoms and culture of $>100,000 \mathrm{CFU} / \mathrm{ml}$ of $A$. urinae as the sole uropathogen, verified by the clinical microbiology lab using MALDI-TOF MS as described above. Finally, two strains were cultured from two asymptomatic control patients. Of note, the three hyperflocking strains were isolated from different patients, collected months apart.

In addition to the 24 clinical strains of $A$. urinae, strains from 3 other Aerococcus species were selected for the genome comparison analysis described below. All three were isolated via the same method and during the same time period as indicated for the $24 \mathrm{~A}$. urinae strains. Aerococcus christensenii (UMB0884) was cultured from an asymptomatic control patient, while Aerococcus sanguinicola (UMB0139) and Aerococcus viridans (UMB0240) were cultured from two different patients with OAB.

In vitro aggregation phenotypes. To observe in vitro phenotypes, all $24 \mathrm{~A}$. urinae strains were first grown on a $5 \%$ sheep blood agar plate (BAP) (BD BBL prepared plated medium) and incubated under $5 \%$ $\mathrm{CO}_{2}$ atmospheric conditions at $35^{\circ} \mathrm{C}$ for $48 \mathrm{~h}$. To observe the flocking phenotype, A. urinae was subcultured in either tryptic soy broth (TSB) or brain heart infusion broth (BHIB) and then grown statically under $5 \% \mathrm{CO}_{2}$ atmospheric conditions at $35^{\circ} \mathrm{C}$ for $48 \mathrm{~h}$. To observe the hockey puck phenotype, $A$. urinae was subcultured onto either tryptic soy agar (TSA) plates supplemented with $0.5 \%$ glucose (TSA + Glu) or brain heart infusion (BHI) agar plates supplemented with $0.5 \%$ glucose $(\mathrm{BHI}+\mathrm{Glu})$ and grown under $5 \%$ $\mathrm{CO}_{2}$ atmospheric conditions at $35^{\circ} \mathrm{C}$ for $48 \mathrm{~h}$. Experiments to observe the in vitro phenotypes were performed in triplicates more than 20 times.

DNA extraction. Each of the $24 \mathrm{~A}$. urinae strains and the three Aerococcus sp. strains were grown on $5 \%$ sheep blood agar plates (BAPs) (BD BBL prepared plated medium) under $5 \% \mathrm{CO}_{2}$ conditions for 48 $\mathrm{h}$ and then pelleted. To extract genomic DNA, cells were resuspended in $0.5 \mathrm{ml}$ DNA extraction buffer (20 mM Tris-Cl, $2 \mathrm{mM}$ EDTA, 1.2\% Triton X-100, pH 8) followed by the addition of $50 \mu$ lysozyme $(20 \mathrm{mg} / \mathrm{ml})$ and $30 \mu \mathrm{l}$ mutanolysin. After a $1-\mathrm{h}$ incubation at $37^{\circ} \mathrm{C}, 80 \mu \mathrm{l} 10 \%$ SDS and $20 \mu \mathrm{l}$ proteinase $\mathrm{K}$ were added, followed by $2 \mathrm{~h}$ of incubation at $55^{\circ} \mathrm{C}$. Then, $210 \mu \mathrm{l}$ of $6 \mathrm{M} \mathrm{NaCl}$ and $700 \mu \mathrm{l}$ phenolchloroform were added. After a 60-min incubation with rotation, the solution was centrifuged at $13,500 \mathrm{rpm}$ for $10 \mathrm{~min}$, and the aqueous phase extracted. An equivalent volume of isopropanol was added; after a 10-min incubation, the solution was centrifuged at 13,500 rpm for $10 \mathrm{~min}$. The supernatant was decanted, and the DNA pellet was precipitated using $600 \mu \mathrm{l} 70 \%$ ethanol. Following ethanol evaporation, the DNA pellet was resuspended in nuclease-free $\mathrm{H}_{2} \mathrm{O}$ and stored at $-20^{\circ} \mathrm{C}$.

Genome sequencing, assembly, and annotation. Genomic DNA was diluted in water to a concentration of $0.2 \mathrm{ng} / \mu \mathrm{l}$. Library preparation was performed using the Nextera XT DNA library preparation kit (Illumina) according to the manufacturer's instructions with $1 \mathrm{ng}$ of input DNA. Each strain was sequenced using the Illumina MiSeq platform and the MiSeq reagent kit v2 (300 cycles) to produce 150-bp paired-end reads. Sequencing reads were parsed into individual folders according to the respective barcodes. The resulting sequence reads were trimmed with Sickle (30), and the assembly was performed using the SPAdes assembler (31).

Phylogenetic analysis and average nucleotide identity analysis. The phylogenetic analysis was conducted by extracting amino acid sequences for 40 universal single copy marker genes $(32,33)$ from the Aerococcus genomes using Specl (34). A. christensenii (UMB0884), A. sanguinicola (UMB0139), and $A$. viridans (UMB0240) were used to root the tree of all $24 A$. urinae strains and the 5 publicly available strains of $A$. urinae. The protein sequences were concatenated and aligned with MAFFT v. 7.20 (35), and maximum likelihood trees were constructed using FastTree (36) with default settings. All phylogenetic trees were visualized in ITOL (37).

Cytotoxicity assay. To test the cytotoxicity of $A$. urinae cells, HUCs were stained with a trypan blue staining protocol. A. urinae cells were prepared by inoculation in liquid BHI cultures for $48 \mathrm{~h}$ and then standardizing the $48-\mathrm{h}$ culture to an optical density at $600 \mathrm{~nm}\left(\mathrm{OD}_{600}\right)$ of 1.0 before resuspending in Dulbecco's modified Eagle's medium (DMEM) supplemented with 5\% fetal bovine serum (FBS). UPEC and GBS strains were prepared by inoculation in liquid BHI cultures for $24 \mathrm{~h}$, standardization of the 24-h culture to an optical $\mathrm{OD}_{600}$ of 1.0, and then resuspension in DMEM plus 5\% FBS. L. crispatus cells were prepared by inoculation in liquid cultures for $48 \mathrm{~h}$, standardization of the 48 -h culture to an optical OD 600 of 1.0, followed by resuspension in DMEM plus 5\% FBS. The HUC cell line used in these experiments (Huro18H7) was obtained from the bladders of consenting female patients described in a previous study (38). To prepare the HUCs, the day before inoculation, HUCs were counted with a hemocytometer and then diluted to $1 \times 10^{5}$ cells/ml in thymic epithelial (TE) medium (38). Next, 1-ml aliquots of urothelial cells were placed in a 24 -well tissue culture-treated plate and incubated overnight at $37^{\circ} \mathrm{C}$ in $5 \% \mathrm{CO}_{2}$ to allow the cells to adhere to the well. HUCs were treated with the resuspended $A$. urinae, UPEC, GBS, or L. crispatus. As a control, bacteria resuspended in $1 \mathrm{ml}$ of DMEM plus 5\% FBS were also inoculated in a well without urothelial cells. For negative controls, urothelial cells were treated with various toll-like receptor (TLR) agonists: lipopolysaccharide (LPS) (20 ng; Enzo Life Sciences), Pam2 (20 ng; InvivoGen), and Pam3 (30 ng; InvivoGen). After $3 \mathrm{~h}$ of treatment, the percent viability of the urothelial cells was measured with trypan blue (Lonza) staining for dead cells. In addition, bacterial cells were plated for CFU prior to and after treatment of the urothelial cells. 
Functional genomic analysis. Each genome was annotated using RAST (39). A custom python script was written to conduct reciprocal blastp queries using the BLAST+ package (40) in order to identify homologous genes among the A. urinae genomes. Referring to RAST-predicted annotations, function assignments were made for each identified gene family. Custom python scripts were developed to identify gene families associated within phenotypic and phylogenetic groups.

Functional analysis also was performed using RAST. RAST gene annotations utilize the manually curated hierarchical subsystem library (41), which includes functional assignment covering all modules of cellular machinery. A custom python script was written to identify the number of unique coding regions for each genome and each level of functional classification: category, subcategory, subsystem, and role. Next, pairwise genome comparisons of the number of unique coding regions for each level of functional classification were conducted. Presence/absence statistics were calculated for all genomes for each functional classification and manually inspected further.

Data availability. Raw sequence data and assembled genomes were deposited in NCBI's SRA and WGS databases, respectively. SRA record numbers are SRR6973109 through SRR6973128, and WGS record numbers are QMGT00000000 through QMHM00000000.

\section{SUPPLEMENTAL MATERIAL}

Supplemental material is available online only.

SUPPLEMENTAL FILE 1, PDF file, 1.1 MB.

\section{ACKNOWLEDGMENTS}

We thank Thomas Halverson and Grainne McAndrew for their help with the Aerococcus in vitro phenotypes.

This study was funded in part by NIH grants R01DK104718 (to A.J.W.), P50 DK064540-11 (SJH project II to A.L.L.) and K01 DK110225-01A1 (to N.M.G.).

\section{REFERENCES}

1. Fouts DE, Pieper R, Szpakowski S, Pohl H, Knoblach S, Suh MJ, Huang ST, Ljungberg I, Sprague BM, Lucas SK, Torralba M, Nelson KE, Groah SL. 2012. Integrated next-generation sequencing of 16S rDNA and metaproteomics differentiate the healthy urine microbiome from asymptomatic bacteriuria in neuropathic bladder associated with spinal cord injury. J Transl Med 10:174. https://doi.org/10.1186/1479-5876-10-174.

2. Hilt EE, McKinley K, Pearce MM, Rosenfeld AB, Zilliox MJ, Mueller ER, Brubaker L, Gai X, Wolfe AJ, Schreckenberger PC. 2014. Urine is not sterile: use of enhanced urine culture techniques to detect resident bacterial flora in the adult female bladder. J Clin Microbiol 52:871-876. https://doi.org/10.1128/JCM.02876-13.

3. Khasriya R, Sathiananthamoorthy S, Ismail S, Kelsey M, Wilson M, Rohn JL, Malone-Lee J. 2013. Spectrum of bacterial colonization associated with urothelial cells from patients with chronic lower urinary tract symptoms. J Clin Microbiol 51:2054-2062. https://doi.org/10.1128/JCM .03314-12.

4. Wolfe AJ, Toh E, Shibata N, Rong R, Kenton K, Fitzgerald M, Mueller ER, Schreckenberger P, Dong Q, Nelson DE, Brubaker L. 2012. Evidence of uncultivated bacteria in the adult female bladder. J Clin Microbiol 50:1376-1383. https://doi.org/10.1128/JCM.05852-11.

5. Pearce MM, Hilt EE, Rosenfeld AB, Zilliox MJ, Thomas-White K, Fok C, Kliethermes S, Schreckenberger P, Brubaker L, Gai X, Wolfe AJ. 2014. The female urinary microbiome: a comparison of women with and without urgency urinary incontinence. mBio 5:e01283-14. https://doi.org/10 .1128/mBio.01283-14.

6. Price TK, Dune T, Hilt EE, Thomas-White KJ, Kliethermes S, Brincat C, Brubaker L, Wolfe AJ, Mueller ER, Schreckenberger P. 2016. The clinical urine culture: enhanced techniques improve detection of clinically relevant microorganisms. J Clin Microbiol 54:1216-1222. https://doi.org/ 10.1128/jcm.00044-16.

7. Kline KA, Lewis AL. 2016. Gram-positive uropathogens, polymicrobial urinary tract infection, and the emerging microbiota of the urinary tract. Microbiol Spectr 4:UTI-0012-2012. https://doi.org/10.1128/microbiolspec .UTI-0012-2012.

8. Aguirre M, Collins MD. 1992. Phylogenetic analysis of some Aerococcuslike organisms from urinary tract infections: description of Aerococcus urinae sp. nov. J Gen Microbiol 138:401-405. https://doi.org/10.1099/ 00221287-138-2-401.

9. Rasmussen M. 2016. Aerococcus: an increasingly acknowledged human pathogen. Clin Microbiol Infect 22:22-27. https://doi.org/10.1016/j.cmi .2015.09.026.
10. Senneby E, Goransson L, Weiber S, Rasmussen M. 2016. A populationbased study of aerococcal bacteraemia in the MALDI-TOF MS-era. Eur J Clin Microbiol Infect Dis 35:755-762. https://doi.org/10.1007/s10096-016 -2594-z.

11. Yabes JM, Perdikis S, Graham DB, Markelz A. 2018. A rare case of Aerococcus urinae infective endocarditis in an atypically young male: case report and review of the literature. BMC Infect Dis 18:522. https:// doi.org/10.1186/s12879-018-3414-0.

12. Forsvall A, Wagenius M, Rasmussen M. 2019. Perigenital necrotizing soft tissue infection caused by Aerococcus urinae. IDCases 18:e00590. https:// doi.org/10.1016/j.idcr.2019.e00590.

13. Greco M, Rúa-Figueroa Í, Ghiglione S, Santana Medina E, Quevedo Abeledo JC, Rodríguez-Lozano C. 2018. Musculoskeletal infections caused by Aerococcus urinae: a case-based review. Clin Rheumatol 37: 2587-2594. https://doi.org/10.1007/s10067-018-4072-8.

14. Cattoir V, Kobal A, Legrand P. 2010. Aerococcus urinae and Aerococcus sanguinicola, two frequently misidentified uropathogens. Scand J Infect Dis 42:775-780. https://doi.org/10.3109/00365548.2010.485576.

15. de Jong MF, Soetekouw R, ten Kate RW, Veenendaal D. 2010. Aerococcus urinae: severe and fatal bloodstream infections and endocarditis. J Clin Microbiol 48:3445-3447. https://doi.org/10.1128/JCM.00835-10.

16. Skov R, Christensen JJ, Korner B, Frimodt-Møller N, Espersen F. 2001. In vitro antimicrobial susceptibility of Aerococcus urinae to 14 antibiotics, and time-kill curves for penicillin, gentamicin and vancomycin. J Antimicrob Chemother 48:653-658. https://doi.org/10.1093/jac/48.5.653.

17. Pearce MM, Zilliox MJ, Rosenfeld AB, Thomas-White KJ, Richter HE, Nager CW, Visco AG, Nygaard IE, Barber MD, Schaffer J, Moalli P, Sung VW, Smith AL, Rogers R, Nolen TL, Wallace D, Meikle SF, Gai X, Wolfe AJ, Brubaker L. 2015. The female urinary microbiome in urgency urinary incontinence. Am J Obstet Gynecol 213:347.e1-347.e11. https://doi.org/ 10.1016/j.ajog.2015.07.009.

18. Flores-Mireles AL, Walker JN, Caparon M, Hultgren SJ. 2015. Urinary tract infections: epidemiology, mechanisms of infection and treatment options. Nat Rev Microbiol 13:269-284. https://doi.org/10.1038/ nrmicro3432.

19. Shannon O, Morgelin M, Rasmussen M. 2010. Platelet activation and biofilm formation by Aerococcus urinae, an endocarditis-causing pathogen. Infect Immun 78:4268-4275. https://doi.org/10.1128/IAI.00469-10.

20. Procop GW, Church DL, Hall GS, Janda WM, Koneman EE, Schreckenberger P, Woods GL. 2017. Neisseria species and Moraxella catarrhalis, 
p 614-656. Koneman's color atlas and textbook of diagnostic microbiology, 7th ed. Wolters Kluwer Health, Philadelphia, PA.

21. Carkaci D, Dargis R, Nielsen XC, Skovgaard O, Fuursted K, Christensen JJ. 2016. Complete genome sequences of Aerococcus christensenii CCUG $28831^{\top}$, Aerococcus sanguinicola CCUG $43001^{\top}$, Aerococcus urinae CCUG $36881^{\top}$, Aerococcus urinaeequi CCUG $28094^{\top}$, Aerococcus urinaehominis CCUG $42038 \mathrm{~B}^{\mathrm{T}}$, and Aerococcus viridans CCUG 4311 ${ }^{\mathrm{T}}$. Genome Announc 4:e00302-16. https://doi.org/10.1128/genomeA.00302-16.

22. Carkaci D, Hojholt K, Nielsen XC, Dargis R, Rasmussen S, Skovgaard O, Fuursted K, Andersen PS, Stegger M, Christensen JJ. 2017. Genomic characterization, phylogenetic analysis, and identification of virulence factors in Aerococcus sanguinicola and Aerococcus urinae strains isolated from infection episodes. Microb Pathog 112:327-340. https://doi.org/10 .1016/j.micpath.2017.09.042.

23. Thomas-White KJ, Hilt EE, Fok C, Pearce MM, Mueller ER, Kliethermes $S$, Jacobs K, Zilliox MJ, Brincat C, Price TK, Kuffel G, Schreckenberger P, Gai X, Brubaker L, Wolfe AJ. 2016. Incontinence medication response relates to the female urinary microbiota. Int Urogynecol J 27:723-733. https:// doi.org/10.1007/s00192-015-2847-x.

24. Birder L, Andersson KE. 2013. Urothelial signaling. Physiol Rev 93: 653-680. https://doi.org/10.1152/physrev.00030.2012.

25. Ouyang J, Shao X, Li J. 2000. Indole-3-glycerol phosphate, a branchpoint of indole-3-acetic acid biosynthesis from the tryptophan biosynthetic pathway in Arabidopsis thaliana. Plant J 24:327-333. https://doi.org/10 .1046/j.1365-313x.2000.00883.x

26. Spaepen S, Vanderleyden J. 2011. Auxin and plant-microbe interactions. Cold Spring Harb Perspect Biol 3:a001438. https://doi.org/10.1101/ cshperspect.a001438.

27. Lee J-h, Lee J. 2010. Indole as an intercellular signal in microbial communities. FEMS Microbiol Rev 34:426-444. https://doi.org/10.1111/j.1574 $-6976.2009 .00204 . x$

28. Barr-Beare E, Saxena V, Hilt EE, Thomas-White K, Schober M, Li B, Becknell B, Hains DS, Wolfe AJ, Schwaderer AL. 2015. The interaction between Enterobacteriaceae and calcium oxalate deposits. PLoS One 10:e0139575. https://doi.org/10.1371/journal.pone.0139575.

29. Dune TJ, Price TK, Hilt EE, Thomas-White KJ, Kliethermes S, Brincat C, Brubaker L, Schreckenberger P, Wolfe AJ, Mueller ER. 2017. Urinary symptoms and their associations with urinary tract infections in urogynecologic patients. Obstet Gynecol 130:718-725. https://doi.org/10 .1097/AOG.0000000000002239.

30. Joshi NA, Fass JN. 2011. Sickle: a sliding-window, adaptive, quality-based trimming tool for FastQ files (version 1.33). https://github.com/najoshi/ sickle.

31. Bankevich A, Nurk S, Antipov D, Gurevich AA, Dvorkin M, Kulikov AS,
Lesin VM, Nikolenko SI, Pham S, Prjibelski AD, Pyshkin AV, Sirotkin AV, Vyahhi N, Tesler G, Alekseyev MA, Pevzner PA. 2012. SPAdes: a new genome assembly algorithm and its applications to single-cell sequencing. J Comput Biol 19:455-477. https://doi.org/10.1089/cmb.2012.0021.

32. Ciccarelli FD, Doerks T, von Mering C, Creevey CJ, Snel B, Bork P. 2006 Toward automatic reconstruction of a highly resolved tree of life. Science 311:1283-1287. https://doi.org/10.1126/science.1123061.

33. Sorek R, Zhu Y, Creevey CJ, Francino MP, Bork P, Rubin EM. 2007 Genome-wide experimental determination of barriers to horizontal gene transfer. Science 318:1449-1452. https://doi.org/10.1126/science .1147112 .

34. Mende DR, Sunagawa S, Zeller G, Bork P. 2013. Accurate and universal delineation of prokaryotic species. Nat Methods 10:881-884. https://doi .org/10.1038/nmeth.2575.

35. Katoh K, Standley DM. 2013. MAFFT multiple sequence alignment software version 7: improvements in performance and usability. Mol Biol Evol 30:772-780. https://doi.org/10.1093/molbev/mst010.

36. Price MN, Dehal PS, Arkin AP. 2009. FastTree: computing large minimum evolution trees with profiles instead of a distance matrix. Mol Biol Evol 26:1641-1650. https://doi.org/10.1093/molbev/msp077.

37. Letunic I, Bork P. 2011. Interactive Tree Of Life v2: online annotation and display of phylogenetic trees made easy. Nucleic Acids Res 39: W475-W478. https://doi.org/10.1093/nar/gkr201.

38. Huddleston JR. 2014. Horizontal gene transfer in the human gastrointestinal tract: potential spread of antibiotic resistance genes. Infect Drug Resist 7:167-176. https://doi.org/10.2147/IDR.S48820.

39. Aziz RK, Bartels D, Best AA, DeJongh M, Disz T, Edwards RA, Formsma K, Gerdes S, Glass EM, Kubal M, Meyer F, Olsen GJ, Olson R, Osterman AL, Overbeek RA, McNeil LK, Paarmann D, Paczian T, Parrello B, Pusch GD, Reich C, Stevens R, Vassieva O, Vonstein V, Wilke A, Zagnitko O. 2008. The RAST server: rapid annotations using subsystems technology. BMC Genomics 9:75. https://doi.org/10.1186/1471-2164-9-75.

40. Camacho C, Coulouris G, Avagyan V, Ma N, Papadopoulos J, Bealer K, Madden TL. 2009. BLAST+: architecture and applications. BMC Bioinformatics 10:421. https://doi.org/10.1186/1471-2105-10-421.

41. Overbeek R, Begley T, Butler RM, Choudhuri JV, Chuang HY, Cohoon M, de Crecy-Lagard V, Diaz N, Disz T, Edwards R, Fonstein M, Frank ED, Gerdes S, Glass EM, Goesmann A, Hanson A, Iwata-Reuyl D, Jensen R, Jamshidi N, Krause L, Kubal M, Larsen N, Linke B, McHardy AC, Meyer F, Neuweger $\mathrm{H}$, Olsen G, Olson R, Osterman A, Portnoy V, Pusch GD, Rodionov DA, Ruckert C, Steiner J, Stevens R, Thiele I, Vassieva O, Ye Y, Zagnitko O, Vonstein V. 2005. The subsystems approach to genome annotation and its use in the project to annotate 1000 genomes. Nucleic Acids Res 33:5691-5702. https://doi.org/10.1093/nar/gki866. 